\title{
An analysis of the water soluble components of Sappi Saiccor's effluent streams
}

\author{
F Ismail*, DA Mulholland and JJ Marsh \\ School of Chemistry, University of KwaZulu-Natal, Howard College Campus, Durban 4041, South Africa
}

\begin{abstract}
Sappi Saiccor is a pulp mill that produces high-grade chemical cellulose (dissolving pulp) from predominantly hardwood timber and is currently the world's largest manufacturer of this type of pulp. Attempts to isolate pure lignosulphonates were unsuccessful; however, an acid hydrolysis of the aqueous portion of the calcium effluent stream yielded a range of organic compounds. These included lignans, lignin-type precursors as well as small quantities of vanillin and syringaldehyde. The structures of these compounds were determined using NMR spectroscopic and mass spectrometric techniques.
\end{abstract}

Keywords: effluent, acid hydrolysis, lignan, lignosulphonates, dissolving pulp

\section{Introduction}

The Sappi Saiccor factory is situated at Umkomaas, $50 \mathrm{~km}$ south of Durban. It is the world's single largest manufacturer of chemical cellulose with the capacity to produce up to $560000 \mathrm{t}$ of dissolving pulp per year (depending on grade mix), most of which is exported to Europe, America and Asia. It is also renowned for being the first company to produce high-grade chemical cellulose from the Eucalyptus tree (Thubron, 2002). Sappi Saiccor is one of the few pulp mills that produces chemical cellulose by the acid sulphite process, using both calcium $(\mathrm{Ca})$ and magnesium $(\mathrm{Mg})$ as bases. The wood chips are cooked in large digesters with liquor under high temperature $\left(140^{\circ} \mathrm{C}\right)$ and pressure $(10 \mathrm{bar})$. This process renders the lignin and hemicellulose in the wood soluble, so that it can then be washed out into the effluent streams. The four main streams of non-recovered effluent, that is, the calcium spent liquor, the magnesium pulp condensate and the two streams from the bleaching stages combine to form the main effluent stream before being pumped out to sea through a $7 \mathrm{~km}$ pipeline. Thus, the main effluent should contain a large proportion of lignins and lignosulphonates, as the main aim of the process is to produce a high-grade cellulose pulp free of lignin. Other components of the effluent would be hemicelluloses, resin acids, tannins and sugars.

In recent years environmental awareness has significantly increased and this has prompted Sappi Saiccor to discover ways of improving the quality of the mill's effluent before it is disposed of into the sea. At present, a large proportion of the calcium spent liquor effluent is pumped to an adjacent plant, where the crude lignosulphonates are recovered for commercial purposes (Thubron, 2002). In addition, the effluent from the magnesium pulp section is greatly reduced during the recovery process of the magnesium oxide base material. The only waste going to the effluent stream in this section is in the form of a condensate formed during the evaporation of the liquor. Saiccor's next step has been towards the characterisation of the effluent with the intention of identifying any commercially exploitable compounds, which can be

\footnotetext{
* To whom all correspondence should be addressed.

政 +2731 2603090; fax: +2731 2603091; e-mail: ismailf4@ukzn.ac.za Received 12 August 2004; accepted in revised form 26 August 2005.
}

extracted and marketed, thereby further reducing the impact of their industrial waste effluent on the environment.

The characterisation of pulping liquors has been carried out since the early 1950s. Studies have shown that the spent liquor from chemical pulping contains varying amounts of organic compounds from all wood constituents. The nature and concentrations of these compounds depend largely on the type of wood material used for pulp production, the type of pulping method employed and the composition of the cooking liquors (Sjöström and Alén, 1999).

There are two major chemical pulping processes, viz. sulphate pulping and sulphite pulping. Delignification during both sulphate and sulphite chemical pulping, using various types of bases, produces a complex mixture of products ranging from simple phenolic compounds to large macromolecules. These compounds form the major components of the total dissolved solids present in spent liquor effluents.

The importance of sulphite pulping has decreased during the recent decades, thus most of the information on the composition of sulphite spent liquors dates from the 1950s and 1960s (Sjöström and Alén, 1999). Early studies on the spent liquor of sulphite pulped aspen wood showed the presence of a large number of low-molecular mass aromatic compounds. These compounds were identified as vanillin, syringaldehyde, syringol, 4-hydroxybenzoic acid, dihydroconiferyl alcohol, syringaresinol and $\alpha$-conidendrin (Pearl and Beyer, 1961; Pearl and Beyer, 1964a; Pearl and Beyer, 1964b).

Recent studies have concentrated on the isolation and characterisation of lignosulphonates from spent bisulphite liquor. A large number of sulphonated lignin-derived monomers and dimers have been isolated and identified using high-performance liquid chromatography (HPLC) (Bialski et al., 1986; Luthe, 1990). Examples of such compounds include 1-syringyl-2-propene1-sulphonic acid, methyl-3,4-dimethoxybenzenesulphonate, 3-guiacylpropanal-3-sulphonic acid and 1,2-disulphonomethyl1-(3',4'-dimethoxyphenyl)-propane (Bialski et al., 1986; Luthe, 1990).

Studies of the black liquor obtained from a Eucalyptus globulus bleached Kraft pulp mill showed the presence of many different types of compounds. The ether-soluble fractions were found to contain aromatic acids and phenolic compounds. The major components were identified as syringaldehyde, acetosyringone, syringol and syringaresinol (Neto et al., 1999). Other compounds 


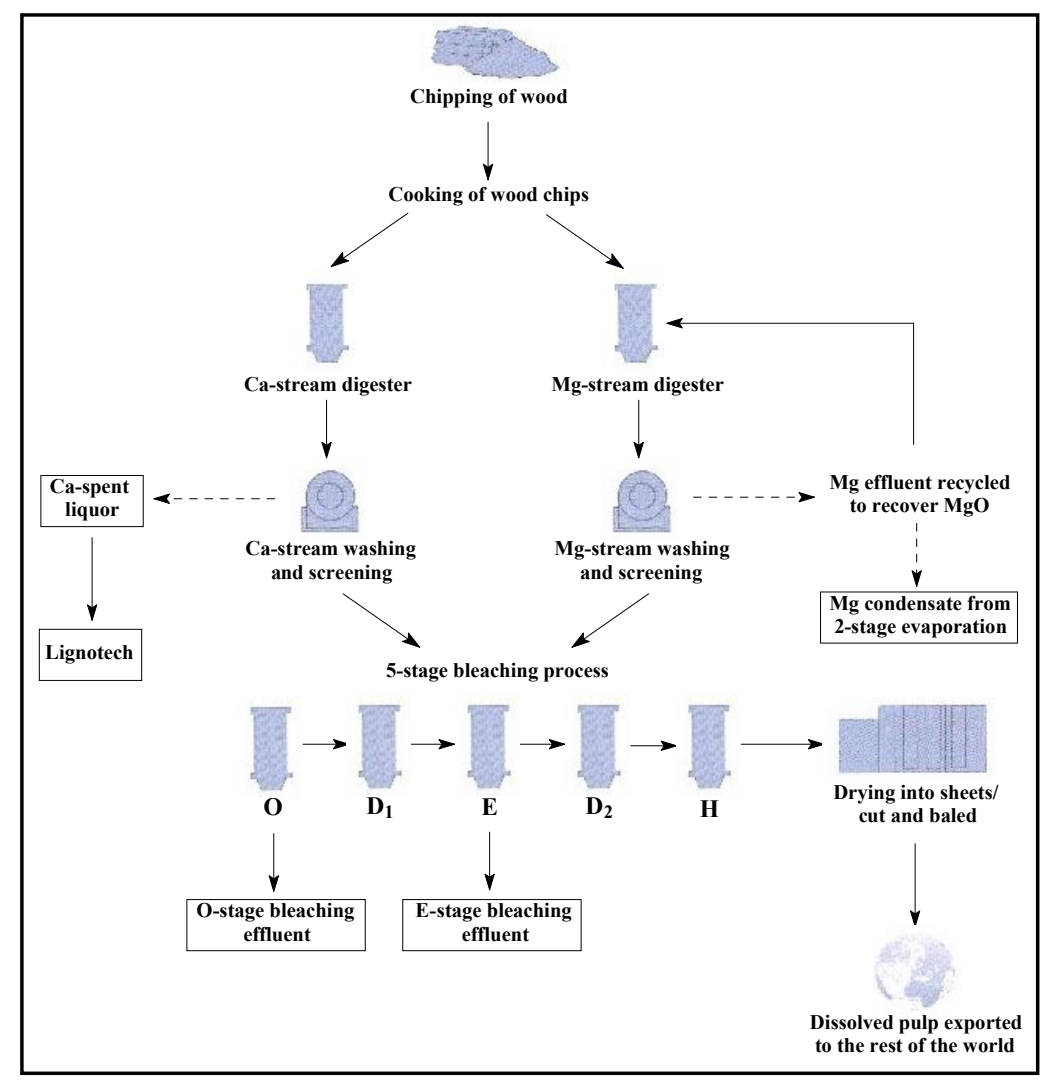

Figure 1

Simplified flowchart of Sappi Saiccor's process (Moodley et al., 2003a)

\section{Experimental}

\section{Sampling procedure}

The calcium spent liquor effluent was sampled after the washing and screening stages as the waste spent liquor goes to the effluent drain but before it is pumped to the adjacent plant for the recovery of crude lignosulphonates. During pumping the sample is generally under high pressures to maintain a continuous flow through the pipelines, which results in a high velocity and ensures the homogeneity of the effluent sample. The sample was collected in plastic containers from a sampling spigot of a storage tank. The collected sample had a temperature of between 85 and $100^{\circ} \mathrm{C}$ and $\mathrm{a} \mathrm{pH}$ of between 1 and 2 .

\section{Lignosulphonate extraction procedure (Kontturi and Sundholm, 1986; Lin, 1992)}

\section{Step 1}

A liquid ion exchanger was prepared by mixing $1 \mathrm{M} \mathrm{HCl}(150 \mathrm{~m} \ell)$ with a solution of dodecylamine in butanol for $10 \mathrm{~min}$ in a separating funnel.

\section{Step 2}

Equal volumes of the liquid ion exchanger (mass $=100.37 \mathrm{~g}$ ) and calcium spent liquor (mass $=$ $77.36 \mathrm{~g}$ ) were added together and the mixture was stirred continuously for $30 \mathrm{~min}$ at a tem-

isolated from these fractions included vanillic acid, acetovanillone, 1,1'-disyringylethane, 2,6-dimethoxyhydroquinone, 4,4'dihydroxy-3,3'-dimethoxystilbene and aspidinol (Neto et al., 1999). A number of aliphatic carboxylic acids, such as lactic acid, 2-hydroxy acetic acid and oxalic acid, were also isolated from the liquid phase of the black liquor (Neto et al., 1999). The watersoluble fractions contained predominantly carbohydrates with xylose and galactose as the major sugars (Neto et al., 1999).

A preliminary study on Sappi Saiccor pulp mill's effluent concentrated on the characterisation of the compounds contained in the neutral organic extracts of all four effluent streams. A number of known organic compounds were isolated and characterised. These included a mixture of lignan isomers, epi-syringaresinol and meso-syringaresinol and lignin-type precursors such as 3(4'-hydroxy-3',5'-dimethoxyphenyl)-prop-1-ene, 2,6-dimethoxy-1,4-benzoquinone, 3-(4'-hydroxy-3',5'-dimethoxyphenyl)1-hydroxy-propane-2-one, syringaldehyde and vanillin (Moodley et al., 2003a; Moodley et al., 2003b). Lignans are dimeric compounds formed by the combination of two phenylpropanoid units.

The commercial applications of both syringaldehyde and vanillin are extensive, however, these compounds were not isolated in commercially viable quantities from the organic component of the effluent streams and the bulk of the effluent which remained in the aqueous phase was not fully characterised. Thus, the objective of this work was two-fold. Firstly, to extract, separate and identify the remaining water-soluble compounds present, viz. lignosulphonates, which are also of commercial interest and secondly to try and increase the concentrations of vanillin and syringaldehyde obtained by further treatment of the effluent. perature of 49 to $54^{\circ} \mathrm{C}$. The amount of spent liquor was calculated to give an equivalent amount of sulphonic acid groups as the dodecylamine in the ion exchanger (Lin, 1992). This was done using the method of conductometric titration (Beatson, 1992). Thereafter, the two phases were allowed to separate for $2 \mathrm{~h}$ in a separating funnel. The temperature was maintained at 50 to $60^{\circ} \mathrm{C}$ to facilitate phase separation. The top organic layer was removed

\section{Step 3}

The organic layer was adjusted to $\mathrm{pH} 9$ using a $1 \mathrm{M} \mathrm{NaOH}$ solution. The mixture was again allowed to separate for $24 \mathrm{~h}$ at a temperature of 50 to $60^{\circ} \mathrm{C}$. The bottom aqueous layer was extracted with $3 \times 100 \mathrm{~m} \ell$ portions of butanol to remove as much of the amine as possible. Thereafter, the aqueous layer was evaporated on a BUCHI Rotavapor and a creamish-brown precipitate of mass $0.81 \mathrm{~g}(\mathrm{w} / \mathrm{w} \%=1.05 \%)$ was collected.

The brown-coloured precipitate was found to be insoluble in dichloromethane $\left(\mathrm{MeCl}_{2}\right)$ and methanol $(\mathrm{MeOH})$ but soluble in water. A solution of the sample dissolved in water was left to air evaporate producing white square-shaped crystals resembling sugar granules. The precipitate was subjected to an ignition test by heating a sample on a crucible lid. The sample melted easily forming a black residue. No smoke was given off but a characteristic odour of burnt sugar was produced. However, a Lassaigne sodium fusion test performed on the precipitate gave a positive result for the presence of sulphur. The ${ }^{1} \mathrm{H}$ and ${ }^{13} \mathrm{C}$ NMR spectra indicated that the precipitate contained a mixture of aromatic compounds and sugar molecules with the proportion of sugars being much greater. Poor separation was obtained on thin layer chromatography plates and preparative and used in 3 . 
STEP 1: Preparation of liquid ion exchanger, amine hydrochloride

$$
\mathrm{R}_{1} \mathrm{R}_{2} \mathrm{R}_{3} \mathrm{~N}+\mathrm{HCl} \longrightarrow \mathrm{R}_{1} \mathrm{R}_{2} \mathrm{R}_{3} \mathrm{NHCl}
$$

STEP 2: Formation and extraction of the lignosulphonate - amine complex

Scheme 1

The chemical reactions occurring during the amine extraction of lignosulphonates

(Kontturi and Sundholm, 1986; Lin, 1992)

$$
\text { Lignin- } \mathrm{SO}_{3}^{-} \mathrm{H}^{+}+\mathrm{R}_{1} \mathrm{R}_{2} \mathrm{R}_{3} \mathrm{NHCl} \longrightarrow \underset{(\text { complex })}{\operatorname{Lignin}-\mathrm{SO}_{3}^{-} \mathrm{N}^{+} \mathrm{HR}_{1} \mathrm{R}_{2} \mathrm{R}_{3}}+\mathrm{HCl}
$$

STEP 3 : Regeneration of the lignosulphonate with an alkali

$$
\underset{\text { (complex) }}{\operatorname{Lignin}-\mathrm{SO}_{3}^{-} \mathrm{N}^{+} \mathrm{HR}_{1} \mathrm{R}_{2} \mathrm{R}_{3}}+\mathrm{NaOH} \longrightarrow \underset{(\mathrm{Na}-\mathrm{salt})}{\operatorname{Lignin}-\mathrm{SO}_{3} \mathrm{Na}}+\underset{\mathrm{NR}_{1} \mathrm{R}_{2} \mathrm{R}_{3}}{\operatorname{Li}}+\mathrm{H}_{2} \mathrm{O}
$$




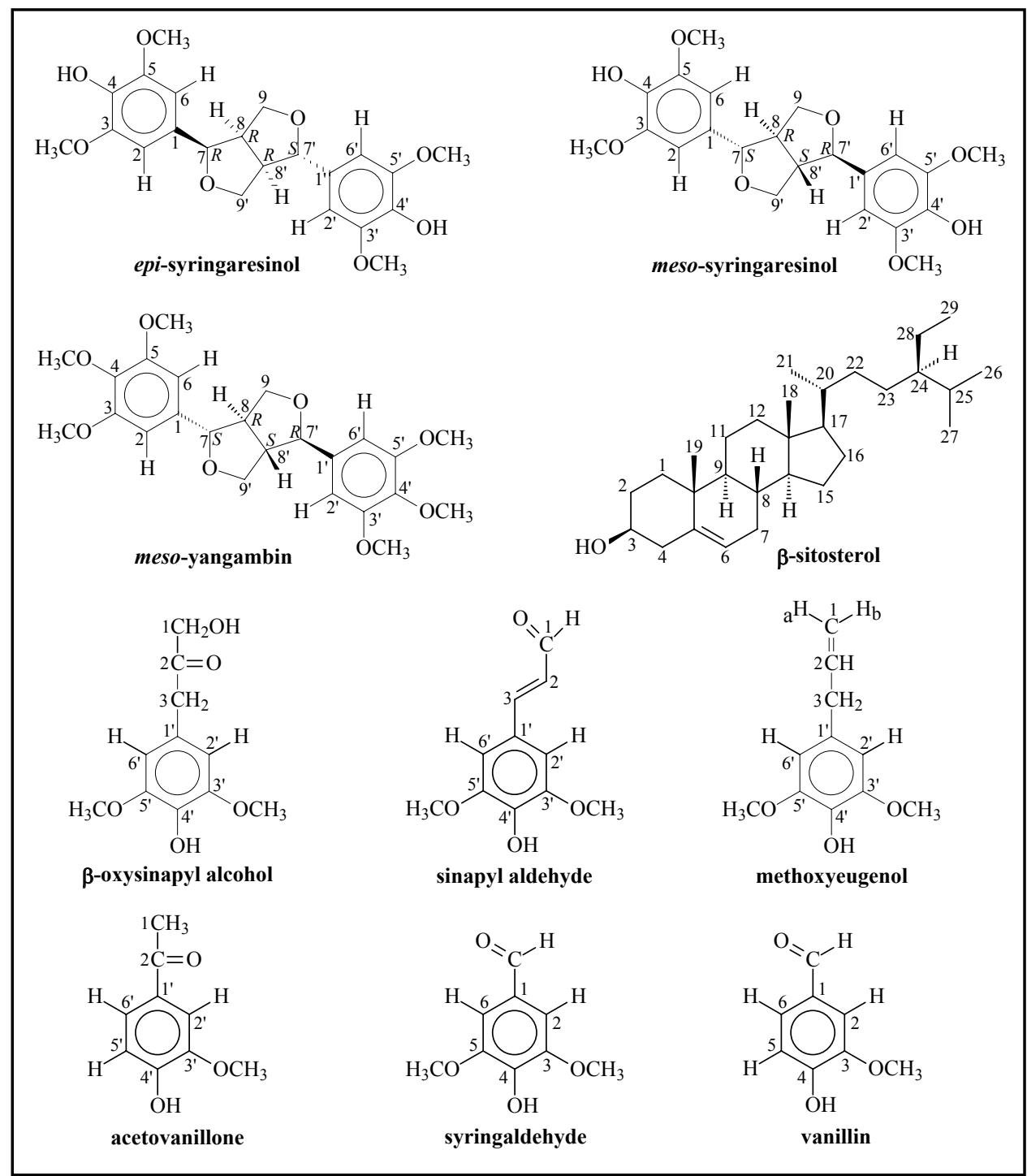

Figure 2

Structures of compounds isolated was calibrated against an air background. The compounds were analysed using a $\mathrm{NaCl}$ window with dichloromethane as the solvent. All data were acquired using the OMNIC software. Ultraviolet absorption spectra were obtained on a Varian Cary 1E double beam UV-visible spectrophotometer. The UV spectra of the isolated organic compounds were run in dichloromethane using matched quartz cuvettes and the instrument was calibrated against dichloromethane.

All samples were injected manually, using a $1 \mu \ell$ syringe, onto a HP5-MS column in the gas chromatography-mass spectrometer (GC-MS) with a 1:50 split ratio. The starting temperature was $50^{\circ} \mathrm{C}$ and the sample was held at this temperature for $2 \mathrm{~min}$. The temperature was then ramped at $20^{\circ} \mathrm{C} / \mathrm{min}$ until a temperature of $300^{\circ} \mathrm{C}$ was reached. Thereafter, the sample was held for a further $15 \mathrm{~min}$ at this maximum temperature. A solvent delay of 2 min was set. Low-resolution mass spectrometry was carried out on an Agilent 5973 mass spectrometer connected to a $6890 \mathrm{GC}$.

The melting points of all the organic compounds isolated were determined using a Kofler micro-hot stage melting point apparatus and are uncorrected. Optical rotations were measured using a Perkin Elmer Model 341 Polarimeter. A quartz Microcell with a tube length of $100 \mathrm{~mm}$ and a volume of $1.0 \mathrm{~m} \ell$ was used. The samples were recorded at $20.0^{\circ} \mathrm{C}$ in chloroform.

\section{Results and discussion}

Acid hydrolysis of the calcium spent liquor resulted in the depolymerisation of the lignin molecule releasing more lignin monomers and dimers into the organic phase.

The major component isolated from the organic portion of the hydrolysed calcium spent liquor was a creamish-white crystalline solid, identified as the lignan epi-syringaresinol. The mass spectrum of compound 1 showed a molecular ion $\left[\mathrm{M}^{+}\right]$peak at $m /$ $z 418$, which corresponded to a molecular formula of $\mathrm{C}_{22} \mathrm{H}_{26} \mathrm{O}_{8}$. The number of carbon atoms corresponded to twice those of a phenylpropanoid monomer suggesting that compound $\mathbf{1}$ had a dimeric structure, as in a lignan molecule. The ${ }^{1} \mathrm{H},{ }^{13} \mathrm{C}, \mathrm{HSQC}$, HMBC and COSY NMR spectra were used to determine the structure of this compound and the relative stereochemistry of the molecule was determined from the 2D-NOESY NMR spectrum. The approximate concentration of epi-syringaresinol in the hydrolysed aqueous phase of the calcium spent liquor effluent was $0.014 \mathrm{~g} / \ell$.

Compound 2 was isolated as an inseparable mixture with compound 1 (epi-syringaresinol). It was identified as a stereoisomer of compound $\mathbf{1}$ in that it had the same molecular structure and formula but the stereochemistry at the chiral centres of the two tetrahydrofuran rings was different. The structure of 
compound 2 was fully elucidated by subtracting the peaks of the known compound, epi-syringaresinol. The ${ }^{1} \mathrm{H}$ and ${ }^{13} \mathrm{C}$ NMR spectra of compound $\mathbf{2}$ (with epi-syringaresinol impurity peaks subtracted) showed fewer peaks than those seen for compound 1, which indicated that this compound was symmetrical. The intensity of the carbon resonances for compound $\mathbf{2}$ was twice that of compound $\mathbf{1}$, which suggested that the ratio of compound $\mathbf{2}$ to compound $\mathbf{1}$ in the mixture was 2:1. Compound $\mathbf{2}$ was identified as the stereoisomer of compound $\mathbf{1}$ known as meso-syringaresinol. It is the second major compound isolated from the hydrolysed aqueous phase of the calcium spent liquor effluent stream. The mixture of the two isomers had a combined approximate concentration of $0.142 \mathrm{~g} / \ell$. Taking into consideration that the ratio of compound $\mathbf{2}$ to compound $\mathbf{1}$ in the mixture was 2:1, the approximate concentration of compound $\mathbf{2}$ was, therefore, estimated to be $0.095 \mathrm{~g} / \ell$.

The ${ }^{1} \mathrm{H}$ and ${ }^{13} \mathrm{C}$ NMR spectra of compound 3 were similar to that of compound 2, meso-syringaresinol. Only half of the expected proton and carbon resonances were seen, which suggested that compound $\mathbf{3}$ must also be a lignan with a symmetrical structure. The mass spectrum of compound 3 showed a molecular ion $\left[\mathrm{M}^{+}\right]$peak at $m / z 446$, corresponding to a molecular formula of $\mathrm{C}_{24} \mathrm{H}_{30} \mathrm{O}_{8}$. The ${ }^{13} \mathrm{C}$ NMR spectrum of compound 3 was compared to that of meso-syringaresinol. It showed an extra peak at $\delta 60.8 \mathrm{ppm}$, which confirmed the presence of an extra methoxy group in the structure. The HSQC and HMBC NMR spectra were used to confirm the proposed structure of compound 3. Once again, the NOESY NMR spectrum was used to determine the relative stereochemistry of the molecule. Compound 3 was identified as the dimethyl ether of meso-syringaresinol and was hence named meso-yangambin. The optical rotation was measured to be zero, which confirmed that this was a meso compound. Its approximate concentration in the hydrolysed aqueous phase of the calcium spent liquor effluent was $6.000 \times 10^{-4} \mathrm{~g} / \ell$.

Lignin precursors such as methoxyeugenol $\left(\sim 1.440 \times 10^{-3}\right.$ $\mathrm{g} / \ell), \beta$-oxysinapyl alcohol $\left(\sim 1.164 \times 10^{-3} \mathrm{~g} / \ell\right)$, sinapyl aldehyde $\left(\sim 7.440 \times 10^{-4} \mathrm{~g} / \ell\right)$, acetovanillone $\left(\sim 3.840 \times 10^{-4} \mathrm{~g} / \ell\right)$, vanillin $\left(\sim 1.800 \times 10^{-3} \mathrm{~g} / \ell\right)$ and syringaldehyde $\left(\sim 2.160 \times 10^{-3} \mathrm{~g} / \ell\right)$ were also identified along with the common plant triterpenoid, $\beta$-sitosterol $\left(\sim 4.400 \times 10^{-4} \mathrm{~g} / \ell\right)$.

Using the average plant effluent flow rates of the calcium stream, the quantity of the organic compounds being passed to the main effluent holding was estimated (Table 1) (Thubron, 2002; Moodley, 2001).

\section{Conclusion}

The extraction and isolation of pure lignosulphonates proved to be very difficult, mainly due to the hydrophilic nature of these compounds. The extraction procedure employed yielded a mixture of lignosulphonates with a large proportion of sugars. Attempts to separate and derivatise these mixtures were also unsuccessful. Hydrolysis of the aqueous phase of the calcium spent liquor led to the isolation of a number of commercially viable organic compounds. The major compounds were identified as the lignans meso-syringaresinol, epi-syringaresinol and meso-yangambin. Vanillin and syringaldehyde were also isolated from the hydrolysed spent liquor but in low yields. Further work needs to be done to study selective oxidation of the effluent using various different oxidising agents as well as electrochemical methods of oxidation in an attempt to improve the yields of these compounds.

\begin{tabular}{|l|c|}
\hline \multicolumn{2}{|c|}{ TABLE 1 } \\
$\begin{array}{c}\text { Estimated concentration of compounds } \\
\text { isolated in this work contained in main } \\
\text { effluent holding }\end{array}$ \\
\hline Compounds isolated & $\begin{array}{c}\text { Ca }- \text { spent liquor } \\
\text { Flow rate } ~ 75 \text { m}^{3} / \mathrm{h}\end{array}$ \\
\hline epi-syringaresinol & $\sim 1.050 \mathrm{~kg} / \mathrm{h}$ \\
\hline meso-syringaresinol & $\sim 7.125 \mathrm{~kg} / \mathrm{h}$ \\
\hline meso-yangambin & $\sim 0.045 \mathrm{~kg} / \mathrm{h}$ \\
\hline methoxyeugenol & $\sim 0.108 \mathrm{~kg} / \mathrm{h}$ \\
\hline$\beta$-oxysinapyl alcohol & $\sim 0.087 \mathrm{~kg} / \mathrm{h}$ \\
\hline sinapyl aldehyde & $\sim 0.056 \mathrm{~kg} / \mathrm{h}$ \\
\hline acetovanillone & $\sim 0.029 \mathrm{~kg} / \mathrm{h}$ \\
\hline vanillin & $\sim 0.135 \mathrm{~kg} / \mathrm{h}$ \\
\hline syringaldehyde & $\sim 0.162 \mathrm{~kg} / \mathrm{h}$ \\
\hline$\beta$-sitosterol & $\sim 0.033 \mathrm{~kg} / \mathrm{h}$ \\
\hline
\end{tabular}

\section{Acknowledgements}

The authors wish to express their sincere gratitude to Mr Derek Weightman from Sappi Saiccor for the generous funding of this project. We would also like to acknowledge John Thubron and Tracy Wessels from Sappi Saiccor for their assistance in collecting the required samples during this study and for providing the necessary information regarding the plant's processes. We thank Mr Dilip Jagjivan for running the NMR spectra, Mr Bret Parel for his technical assistance as well as Dr Phil Coombes and Miss Brenda Moodley for their laboratory assistance.

\section{References}

BEATSON RP (1992) Determination of sulfonate groups and total sulphur. In: Lin SY and Dence CW (eds.) Methods in Lignin Chemistry. Springer-Verlag, Berlin. 474-477.

BIALSKI AM, LUTHE CE, FONG JL and LEWIS NG (1986) Sulphitepromoted delignification of wood: identification of paucidisperse lignosulphonates. Can. J. Chem. 64 1336-1343.

KING EG, BRAUNS F and HIBBERT H (1935) Lignin sulphonic acid - A preliminary investigation on its isolation and structure. Can. J. Res. 13 (B) 88-102.

KONTTURI A-K and SUNDHOLM G (1986) The extraction and fractionation of lignosulphonates with long chain aliphatic amines. Acta Chem. Scand. A40 121-125.

LIN SY (1992) Commercial spent pulping liquors. In: Lin SY and Dence CW (eds.) Methods in Lignin Chemistry. Springer-Verlag, Berlin. 75-80.

LUTHE CE (1990) Isolation and characterisation of lignosulphonates from an ultra high yield neutral sulphite pulping effluent. Holzforschung 44 107-112.

LUTHE CE and LEWIS NG (1986) Identification and characterisation of paucidisperse lignosulphonates. Holzforschung 40 153-157.

MOODLEY B (2001) Characterisation of SAPPI SAICCOR Pulp Mill's Effluent. Unpublished M.Sc. Dissertation, School of Pure and Applied Chemistry, University of Natal, Durban.

MOODLEY B, MULHOLLAND DA and MARSH JJ (2003a) The characterisation of organic components in the calcium and magnesium effluent streams at Sappi Saiccor. Water SA 29 (3) 237-240.

MOODLEY B, MULHOLLAND DA and MARSH JJ (2003b) The characterisation of organic components in the o- and e-stage bleaching effluent streams at Sappi Saiccor. Water SA 29 (3) 241-243.

NETO CP, BELINO E, EVTUGUIN D and SILVESTRE AJD (1999) Total fractionation and analysis of organic components of industrial Eucalyptus globulus Kraft black liquor. Appita 52 213-217.

PEARL IA and BEYER DL (1961) Studies on the chemistry of aspenwood. VII. Further studies on ether extractives of commercial aspen spent sulfite liquor. J. Org. Chem. 26 546-550. 
PEARL IA and BEYER DL (1964a) Studies on the chemistry of aspenwood. XVII. The ether-insoluble, water-soluble components of aspen spent sulfite liquor. Tappi 47 458-462.

PEARL IA and BEYER DL (1964b) The ether-insoluble, water-soluble components of several spent sulfite liquors. Tappi 47 779-782.
SJÖSTRÖM E and ALÉN R (1999) Analytical Methods in Wood Chemistry Pulping and Papermaking. Springer, Berlin. 193-220.

THUBRON J (2002) Personal communication. Technical Process Manager at Sappi Saiccor. 